\title{
Cross-sectional study reveals a high prevalence of vitamin D deficiency among healthy school children in central Kerala, India
}

\author{
Ayyappan Anitha1*, Suresh A. Poovathinal'2, Vijitha Viswambharan', Ismail Thanseem², \\ Mahesh M. Vasu' ${ }^{1}$, Ranjitha M. ${ }^{1}$
}

\begin{abstract}
${ }^{1}$ Department of Neurogenetics, ${ }^{2}$ Department of Neurology, Institute for Communicative and Cognitive Neurosciences (ICCONS), Shoranur, Kerala, India
\end{abstract}

Received: 17 December 2018

Accepted: 31 January 2019

\section{*Correspondence: \\ Dr. Ayyappan Anitha, \\ E-mail: anitha.a72@gmail.com}

Copyright: (C) the author(s), publisher and licensee Medip Academy. This is an open-access article distributed under the terms of the Creative Commons Attribution Non-Commercial License, which permits unrestricted non-commercial use, distribution, and reproduction in any medium, provided the original work is properly cited.

\section{ABSTRACT}

Background: Authors examined serum vitamin D status among the healthy school children belonging to the south Indian state of Kerala.

Methods: A cross-sectional study, participants were recruited through medical camps organized in Thrissur and Palakkad districts of central Kerala during the months of March and April 2017. A 174 healthy school children (98 males and 76 females) aged 5-13 years were recruited for the study. The children were found to be healthy on the basis of physical examination by a Paediatrician. None of the children had any symptoms of skeletal deformities. All the children were drug-naive. Data on height, weight, skin color, food habits, physical activities and socio-economic status were recorded. A $2 \mathrm{ml}$ of peripheral blood samples were collected from the participants. Total vitamin D in the serum was estimated by chemiluminescence immunoassay (CLIA).

Results: VDD was observed in $60.92 \%$ and insufficiency in $30.46 \%$ of the participants. Only $8.62 \%$ of the participants had normal vitamin D levels. The mean vitamin D level was $19.93 \mathrm{ng} / \mathrm{ml}$. Males had significantly higher vitamin D levels compared to females. Factors such as age, height, weight, diet, skin color and socio-economic status did not influence vitamin D levels.

Conclusions: This is the first study of vitamin D status among the school-age children of Kerala. This paper adds further evidence to the reports indicating high prevalence of subclinical VDD among children across India and calls for action.

Keywords: Hypovitaminosis D, India, Kerala,Vitamin D

\section{INTRODUCTION}

Vitamin D deficiency (VDD) is a global health problem. Conventionally, VDD was primarily found to lead to rickets in children and osteomalacia and osteoporosis in adults. Furthermore, vitamin D is suggested to have a role in preventing the risk of several chronic illnesses such as neoplasms, autoimmune diseases, infectious diseases, cardiovascular diseases, respiratory diseases, musculoskeletal disorders and neurological disorders. ${ }^{1}$
Worldwide, $\sim 1$ billion people are estimated to have VDD, which in turn, is associated with diverse health consequences. Reports from U.S.A, Europe, Canada, Africa, Australia, Brazil, China, Middle East, Mongolia and New Zealand indicate a high incidence of VDD among adults and children. ${ }^{2-10}$

VDD is very common in India as well. VDD as high as $70-100 \%$ has been reported among the apparently healthy individuals belonging to all age groups (healthy children, 
adolescents, young adults and elderly people) residing in different regions (northern, southern eastern, western) of India, with the incidence being similar among subjects from rural and urban areas. ${ }^{11-13}$

In this cross-sectional study, authors examined serum vitamin D status among healthy school children residing in central Kerala.

\section{METHODS}

A study was approved by the Institutional Ethics Committee of Institute for Communicative and Cognitive Neurosciences (ICCONS) duly constituted according to the guidelines of Indian Council of Medical Research. Written informed consent was obtained from the parents of all the children who were recruited for the study. Healthy school children aged 5-13 years were recruited for this cross-sectional study through medical camps organized in Thrissur and Palakkad districts of central Kerala during the months of March and April 2017. A total of 174 children (98 males and 76 females) participated in the study. The mean age of the participants was $8.99 \pm 1.4$ (mean \pm SD) years. Data on height, weight, skin color, food habits, physical activities and economic status were recorded at the time of sample collection. All the children were found to be healthy on the basis of their medical history and physical examination by a Pediatrician. As per the information from parents almost all children received sufficient sunlight exposure through their outdoor activities. None of the children had any apparent symptoms of skeletal deformities. None of the children had been taking any specific medications for at least 3 months prior to sample collection. A $2 \mathrm{ml}$ of peripheral blood samples were collected by venipuncture in BD vacutainer serum tubes, and serum was separated from the samples. A $200 \mu 1$ of serum sample was used for vitamin D assay. Total vitamin D (consisting of vitamin D2 and vitamin D3, the two bioequivalent forms of vitamin D) was estimated by chemiluminescence immunoassay technique using access $25(\mathrm{OH})$ Vitamin D total assay (Beckman coulter Inc, Brea, CA). The assay was carried out in access 2 immunoassay system (Beckman coulter).

\section{Statistical analysis}

Data distribution was not normal on KolmogorovSmirnov test. Therefore, non-parametric tests were used to find differences among groups (e.g. Mann-Whitney Utest, Kruskal-Wallis test) and to examine correlations between variables (e.g. Spearman correlation test).

\section{RESULTS}

Among the 174 subjects recruited for the study, 106 $(60.92 \%)$ had deficient levels $(<20 \mathrm{ng} / \mathrm{ml})$, while 53 $(30.46 \%)$ had insufficient levels $(21-29 \mathrm{ng} / \mathrm{ml})$ of vitamin D. Only $15(8.62 \%)$ participants had normal vitamin D levels (>30ng/ml) (Figure 1A). The mean vitamin D level was $19.93 \pm 6.6 \mathrm{ng} / \mathrm{ml}$. Severe VDD $(<10 \mathrm{ng} / \mathrm{ml})$ was not observed in any of the participants. Males had significantly higher vitamin D levels compared to females (Mann-Whitney U-test $\mathrm{p}=0.003$ ) (Figure 1B).

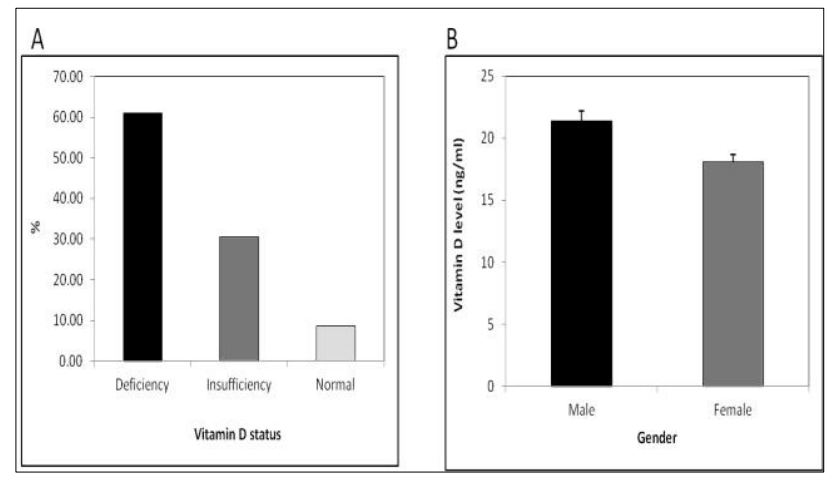

Figure 1: A) Vitamin D status among the study participants, B) males had significantly higher vitamin D levels compared to females.

While the mean vitamin D level in males was $21.37 \pm 7.4$, it was $18.06 \pm 5$ in females. Among the females, $97.37 \%$ $(\mathrm{N}=74)$ were either deficient or insufficient in vitamin $\mathrm{D}$ and only $2.63 \%(\mathrm{~N}=2)$ had normal vitamin D levels. Among the males, $86.73 \%(\mathrm{~N}=85)$ had deficient or insufficient levels of vitamin $\mathrm{D}$ and $13.27 \%(\mathrm{~N}=13)$ had normal vitamin D levels.

There was no significant difference in vitamin D levels between children taking occasional non-vegetarian diet $(\mathrm{N}=55 ; 32.74 \%)$ and frequent non-vegetarian diet $(\mathrm{N}=108 ; 64.28 \%$ ) (Mann-Whitney U-test $\mathrm{p}=0.08)$. Only five participants $(2.98 \%)$ were taking a strictly vegetarian diet. Based on the color of their ration cards, the children were categorized into four groups: most economically backward [yellow card; $\mathrm{N}=6$ (3.80\%)], below poverty line [pink card; $\mathrm{N}=87(55.06 \%)$, above poverty line [blue card; $\mathrm{N}=59$ (37.34\%)], and non-priority [(white card; $\mathrm{N}=6(3.80 \%)]$. There was no significant difference in vitamin D levels between the four groups (KruskalWallis test $\mathrm{p}=0.801)$. Among the participants, 66 children $(38.6 \%)$ had fair skin color, $59(34.5 \%)$ had intermediate skin color, and $46(26.9 \%)$ had dark skin color. There was no significant difference in vitamin $\mathrm{D}$ levels between the three skin colors (Kruskal-Wallis test $\mathrm{p}=0.462$ ). The mean vitamin D levels among children with fair, intermediate and dark skin colors were $21.23 \pm 8.3,19.55 \pm 5.4$ and $18.64 \pm 4.9$ respectively.

There was no significant correlation between age (Spearman's rho=0.08, p=0.307), height (Spearman's rho=0.01, $\mathrm{p}=0.869$ ), weight (Spearman's rho=0.1, $\mathrm{p}=0.093$ ) and vitamin D levels.

\section{DISCUSSION}

In this study, a high prevalence $(60.92 \%)$ of VDD was observed among apparently healthy school children 
residing in central Kerala. Only $8.62 \%$ of the participants had normal vitamin D levels. This is the first study of vitamin D status among the school-age children of Kerala.

VDD is a major health concern in India as in several other countries. Country-wide studies have reported a high incidence of VDD among healthy individuals belonging to all age groups residing in different regions of India. ${ }^{11-13}$ In a hospital-based cross-sectional survey among children aged 6 months to 18 years held in a suburban metropolitan area of Chennai in south India, the prevalence of hypovitaminosis $\mathrm{D}$ was $62.2 \%$, among whom only $3 \%$ had overt rickets. ${ }^{14}$ In another crosssectional study of apparently healthy school children aged 5-10 years belonging to Jaipur in western India, $87.5 \%$ children were found to have sub-optimal/deficient vitamin D levels. ${ }^{15}$ The prevalence of VDD among the school children of Kolkata in eastern India was found to be $61 \% .{ }^{16}$ Marwaha et al, have reported that $90 \%$ of healthy school children in northern India are vitamin D deficient. ${ }^{17}$

There have been only few reports of vitamin D assessment in Kerala population. In a cross-sectional study of 79 children aged 1-5 years conducted in a tertiary care hospital in central Kerala the mean vitamin D level was found to be $18.1 \mathrm{ng} / \mathrm{ml}$, and subclinical VDD was observed in majority of the children even though they neither had rickets nor other clinical abnormalities. ${ }^{18}$ In another cross-sectional study of 140 children aged 3-6 years conducted in the Wayanad district of north Kerala, the mean $25(\mathrm{OH})$ D level was found to be $22.7 \mathrm{ng} / \mathrm{ml}$. VDD was observed in $47.1 \%$, and insufficiency in $35 \%$ of the participants. ${ }^{19}$

About $90 \%$ of vitamin $\mathrm{D}$ is produced by sunshine exposure of skin, and the rest comes from diet. Despite the abundance of sunshine in Kerala, the region registers some of the lowest levels of vitamin D in the country. To prevent VDD, one should spend 15 to 20 minutes daily in the sunshine with $40 \%$ of the skin surface exposed. Even though most of the children who participated in present study engaged in sufficient outdoor activities with $>1$ hour sunlight exposure per day, a high incidence of VDD was observed among them.

Fatty fish, meat, egg and dairy products are good sources of vitamin D. Even though $64.28 \%$ of the participants in this study had been taking non-vegetarian diet frequently, their mean vitamin D level was only $19.7 \mathrm{ng} / \mathrm{ml}$. Concordant with this, vitamin D status among the residents of West Bengal, who consume plenty of fish daily, was found to be as poor as that in other parts of India. $^{20}$ However, Khan et al, observed significant difference in vitamin $\mathrm{D}$ levels between children who consume fish and those who do not consume fish at all. ${ }^{19}$

In this study, $97.37 \%$ of the girls were either deficient or insufficient in vitamin D, and only $2.63 \%$ had normal vitamin D levels. Similarly, in a study conducted in chennai, female children were found to be 1.9 times more at risk of having VDD when compared to males. ${ }^{14}$ Conservative concealed clothing styles and lesser participation in outdoor activities could contribute to decreased cutaneous vitamin D synthesis in females. However, Khan et al observed no significant difference in vitamin D levels between boys and girls. ${ }^{19}$

Serum vitamin D levels are dependent on the season of blood sampling, found to be lowest in winter and highest in summer. ${ }^{16}$ Variation in solar irradiation might have a significant impact upon cutaneous synthesis of vitamin D from sunlight. In a cross-sectional study carried out in northern Kerala, Khan et al, observed significantly higher vitamin D levels in samples collected during summer when compared to other seasons. ${ }^{19}$ In present study, blood samples for vitamin D analysis were collected during the summer months of March and April when the monthly average solar irradiance in Kerala is 6.08 $\mathrm{kwh} / \mathrm{m}^{2} /$ day and $5.08 \mathrm{kwh} / \mathrm{m}^{2} /$ day respectively. Available at: (http://www.synergyenviron.com/tools/solar irradiance/Kerala). In spite of this, a high prevalence of vitamin $\mathrm{D}$ was observed among the participants.

Studies have shown that skin color is relevant to vitamin D synthesis. Individuals with dark skin color have been found to be more often vitamin $\mathrm{D}$ deficient compared to those with light skin color. ${ }^{21}$ However, we did not observe any significant difference in vitamin D levels between children with fair, intermediate and dark skin colors.

There were no significant correlations between vitamin D levels and age, height or weight of the participants. Similar results were observed in a study of vitamin D levels in northern Kerala. ${ }^{19}$

There have been conflicting reports on the impact of socio-economic status on vitamin D levels. While some studies report higher vitamin D levels among low-income families owing to more sunlight exposure, there are reports that indicate a higher prevalence of VDD in lower socio-economic strata. ${ }^{22,23}$ Haider et al, observed that socio-economic conditions do not influence vitamin D levels. ${ }^{24}$ In this study, there was no significant difference in vitamin D levels among individuals above and below the poverty lines. Similar results were observed by Khan et al, ${ }^{19}$ in their study of vitamin D levels in north Kerala.

The exact cut-offs for deficiency and insufficiency of vitamin $\mathrm{D}$ remains controversial among clinicians and researchers. In present study, serum vitamin D level $<20$ $\mathrm{ng} / \mathrm{ml}$ was considered as deficiency and $21-29 \mathrm{ng} / \mathrm{ml}$ as insufficiency, as per the recommendation of US endocrine society. ${ }^{25}$ Subsequently, as per the guidelines of institute of medicine (IOM), it has been estimated that serum vitamin D levels of $20 \mathrm{ng} / \mathrm{ml}$ meets the needs of at least $97.5 \%$ of population across all age groups in developed countries. ${ }^{26}$ According to their criteria, vitamin 
D levels > 20ng/ml indicates vitamin D sufficiency; levels of $15 \mathrm{ng} / \mathrm{ml}$ or less are considered as deficiency,15$20 \mathrm{ng} / \mathrm{ml}$ as insufficiency, and $5 \mathrm{ng} / \mathrm{ml}$ or less as severe deficiency. There is an urgent need to arrive at a consensus on this issue to avoid problems associated with both under- and over- treatment for VDD.

This paper adds further evidence to the reports indicating high prevalence of subclinical VDD among children across India and calls for action. Health care professionals should encourage children to adopt a healthy lifestyle with adequate outdoor activities for optimum sun exposure, and intake of diet rich in vitamin D. Long-term strategies to address this issue include national health policies that recommend screening for VDD, public education on the importance of vitamin D, prevention through supply of fortified food, and treatment with vitamin D supplements.

A limitation of this study is the small sample size; further studies in a larger population are warranted.

\section{ACKNOWLEDGEMENTS}

Authors would like to thank Kerala state council for science, technology and environment (KSCSTE/5167/2017-SRSHS) under the Science Research Schemes (SRS).

Funding: No funding sources Conflict of interest: None declared

Ethical approval: The study was approved by the Institutional Ethics Committee of Institute for Communicative and Cognitive Neurosciences (ICCONS)

\section{REFERENCES}

1. Holick MF. Vitamin D deficiency. N Engl J Med. 2007;357:266-81. https://www.ncbi.nlm.nih.gov/pubmed/17634462

2. Chapuy MC, Preziosi P, Maamer M, Arnaud S, Galan P, Hercberg S, Meunier PJ. Prevalence of vitamin $\mathrm{D}$ insufficiency in an adult normal population. Osteoporosis Int. 1997;7(5):439-3.

3. Whiting SJ, Langlois KA, Vatanparast H, GreeneFinestone LS. The vitamin D status of Canadians relative to the 2011 Dietary Reference Intakes: an examination in children and adults with and without supplement use. Am J Clin Nutr. 2011;94:128-35.

4. Prentice A, Schoenmakers I, Jones KS, Jarjou LMA, Goldberg GR. Vitamin D deficiency and its health consequences in Africa. Clin Rev Bone Miner Metab.2009;7:94-106.

5. Van der Mei IAF, Ponsonby A-L, Engelsen O, Pasco JA, McGrath JJ, Eyles DW, et al. The high prevalence of vitamin D insufficiency across Australian populations is only partly explained by season and latitude. Environ Health Perspect. 2007;115:1132-9.
6. Maeda SS, Kunii IS, Hayashi L, Lazaretti-Castro M. The effect of sun exposure on 25-hydroxyvitamin D concentrations in young healthy subjects living in the city of Sao Paulo, Brazil. Brazilian J Med Biol Res.2007;40:1653-9.

7. Yu S, Fang H, Han J, Cheng X, Xia L, Li S, et al. The high prevalence of hypovitaminosis D in China: a multicenter vitamin D status survey. Med. 2015;94(8).

8. Sedrani SH. Low 25-hydroxyvitamin D and normal serum calcium concentrations in Saudi Arabia: Riyadh region. Ann Nutr Metab. 1984;28:181-5.

9. Rich-Edwards JW, Ganmaa D, Kleinman K, Sumberzul N, Holick MF, Lkhagvasuren T, et al. Randomized trial of fortified milk and supplements to raise 25-hydroxyvitamin $\mathrm{D}$ concentrations in schoolchildren in Mongolia. Am J Clin Nutr. 2011;94:578-4.

https://www.ncbi.nlm.nih.gov/pubmed/21697075

10. Rockell JEP, Skeaff CM, Williams SM, Green TJ. Serum 25-hydroxyvitamin D concentrations of New Zealanders aged 15 years and older. Osteoporos Int. 2006; 17:1382-9.

11. Gupta A. Vitamin D deficiency in India: prevalence, causalities and interventions. Nutrients. 2014;6(2):729 -75.

12. Selvarajan S, Gunaseelan V, Anandabaskar N, Xavier AS, Srinivasamurthy S, Kamalanathan SK, Sahoo JP. Systematic review on vitamin D level in apparently healthy Indian population and analysis of its associated factors. Ind $\mathbf{J}$ Endocrinol Metab 2017;21:765-5.

13. Aparna P, Muthathal S, Nongkynrih B, Gupta SK. Vitamin D deficiency in India. J Family Med Prim Care. 2018;7:324-30.

14. Vasudevan J, Reddy GMM, Jenifer AST, Devi U MR. Prevalence and factors associated with vitamin $\mathrm{D}$ deficiency in Indian children: A hospital based cross sectional study. Pediatric Oncall. 2014;11.

15. Sharawat I, Sitaraman S, Dawman L. Prevalence of vitamin D deficiency among healthy school children in Jaipur district, Rajasthan, India. Int $\mathrm{J}$ Pediatr. 2015;3:801.

16. Basu S, Gupta R, Mitra M, Ghosh A. Prevalence of vitamin $\mathrm{D}$ deficiency in a pediatric hospital of eastern India. Indian J Clin Biochem. 2015;30:1673.

17. Marwaha RK, Tandon N, Reddy DRHK, Aggarwal R, Singh R, Sawhney RC, et al. Vitamin D and bone mineral density status of healthy schoolchildren in northern India. Am J Clin Nutr.2005;82:477-82.

18. Ananda TK, Thuruthiyath N, Thomas EP. Subclinical Vitamin D Deficiency in Children from Thrissur, Kerala. Indian Pediatr. 2018;55(5):434-5.

19. Khan AM, Sindhu TG, Vijayakumar M. Vitamin D status in 3-6-year-old children of Mananthavady ICDS block in Wayanad, Kerala, India. Int J Contemp Pediatr.2018;5:1226-30.

20. Baidya A, Chowdhury S, Mukhopadhyay S, Ghosh S. Profile of vitamin D in a cohort of physicians and 
diabetologists in Kolkata. Indian $\mathrm{J}$ Endocrinol Metab.2012;16:S416-7.

21. Libon F, Cavalier E, Nikkels AF. Skin color is relevant to vitamin D synthesis. Dermatol (Basel) 2013;227:250-4.

22. Garg D, Gupta R, Ahuja J. Association of vitamin D deficiency with demographic factors and socio economic status of parents of Indian children under 5 years of age. Int J Med Sci Edu. 2016;3:373-80.

23. Leger-Guist'hau J, Domingues-Faria C, Miolanne M, Peyrol F, Gerbaud L, Perreira B, et al. Low socio-economic status is a newly identified independent risk factor for poor vitamin D status in severely obese adults. J Hum Nutr Diet. 2017;30:203-15.

24. Haider W, Zaib A, Abbasi A, Saleem A, Mir S, Shah BR, et al. Assessment of vitamin D status in general population of Muzaffarabad district \& effect of supplementation on serum vitamin D levels in general population of Muzaffarabad district. J Nursing Health Sci. 2013;2(1):27-31.
25. Holick MF, Binkley NC, Bischoff-Ferrari HA, Gordon CM, Hanley DA, Heaney RP, et al. Evaluation, treatment, and prevention of vitamin D deficiency: An endocrine society clinical practice guideline. J Clinical Endocrinol Metabol. 2011;96(7):1911-30.

26. Ross AC, Manson JE, Abrams SA, Aloia JF, Brannon PM, Clinton SK, et al. The 2011 report on dietary reference intakes for calcium and vitamin D from the Institute of Medicine: What clinicians need to know. J Clin Endocrinol Metab. 2011;96:53-8.

Cite this article as: Anitha A, Poovathinal SA, Viswambharan V, Thanseem I, Vasu MM, Ranjitha M. Cross-sectional study reveals a high prevalence of vitamin D deficiency among healthy school children in central Kerala, India. Int J Contemp Pediatr 2019;6:867-71. 